\title{
Temporal changes in abundance exhibit less spatial structure than abundance itself in North American birds
}

\author{
Vincenzo A. Ellis ${ }^{1,2} \cdot$ Michael D. Collins ${ }^{3}$
}

Received: 3 May 2018 / Accepted: 10 July 2018 / Published online: 26 July 2018

(c) The Author(s) 2018

\begin{abstract}
Species abundance is often spatially structured such that, within a species' distribution, abundance peaks at one or more areas and declines from those points. Abundance may also increase or decrease over time, but the spatial structure of temporal changes in abundance has been infrequently examined. Here we use count data from the North American Breeding Bird Survey (BBS) to describe the spatial structure of yearly changes in abundance across the distributions of 135 species of land birds. For each species, we calculated the difference in the logarithms of the number of birds counted from one year to the next at survey routes within their distributions. We assessed the spatial structure of yearly changes in abundance using Moran's $I$, a measure of spatial autocorrelation. For comparison, we also calculated Moran's $I$ for abundance, i.e., the logarithm of the number of birds counted on survey routes in each year. As expected, abundance was positively spatially autocorrelated (i.e. closer routes were more similar than expected by chance) at distances of up to a few hundred kilometers for most species. In contrast, changes in abundance showed little to no spatial autocorrelation. Resident species exhibited greater spatial structure in abundance than migrant species; however, the two groups did not differ in the degree of spatial structure in change in abundance. Variation in abundance over multiple years was mostly unrelated to the distance from the abundance-weighted center of species' distributions. Temporal changes in abundance can occur at fine spatial scales for many species, but understanding the causes of such changes is challenging. These results fill a gap in the ecological literature and may have important implications for conservation planning.
\end{abstract}

Keywords Breeding bird survey $\cdot$ Geographic ranges $\cdot$ Macroecology $\cdot$ Population dynamics $\cdot$ Spatial ecology

\section{Zusammenfassung}

Bei nordamerikanischen Vögeln zeigen zeitliche Veränderungen in der Verbreitung ein schwächeres räumliches Muster als die Verbreitung selbst

Die Verbreitung einer Art ist häufig räumlich so strukturiert, dass innerhalb des Verbreitungsgebiets das Auftreten der Art an einem oder mehreren Orten besonders stark ist und abseits dieser Orte abnimmt. Das Vorkommen kann auch über die Zeit zu- oder abnehmen, die räumlichen Muster solcher zeitlicher Änderungen sind bislang aber nur sporadisch untersucht worden. In unserer Studie haben wir Zählungen des North American Breeding Bird Survey (BBS) benutzt, um für 135 Vogelarten die räumlichen Muster im Vorkommen über die Jahre hinweg zu beschreiben. Für jede Art errechneten wir die Differenz der Logarithmen der Anzahl gezählter Vögel eines Jahres und des darauffolgenden entlang einer Strecke innerhalb ihres Verbreitungsgebiets. Dann bestimmten wir das räumliche Muster der jährlichen Schwankungen im Auftreten der Vögel anhand von Mortan's I, einem Maß für räumliche Autokorrelationen. Zum Vergleich berechneten wir auch Mortan's I für das Vorkommen, das heißt, den Logarithmus der Anzahl gezählter Vögel auf dieser Route in jedem Jahr. Wie erwartet, zeigte das Vorkommen der Vögel für die meisten Arten auf Entfernungen von bis zu ein paar hundert Kilometern eine positive

Communicated by C. G. Guglielmo.

Electronic supplementary material The online version of this article (https://doi.org/10.1007/s10336-018-1586-4) contains supplementary material, which is available to authorized users.

Extended author information available on the last page of the article 
Autokorrelation, d.h., das Auftreten der Vögel auf nähergelegenen Strecken war quantitativ ähnlicher, als man es nach einer Zufallsverteilung hätte erwarten können. Im Gegensatz dazu zeigten die Veränderungen im Vorkommen so gut wie keine Autokorrelation. Bei stationären Arten gab es ausgeprägtere räumliche Verbreitungsmuster als bei Zugvögeln, wobei sich beide Gruppen in der Ausprägung der räumlichen Muster der verschiedenen Verbreitungen jedoch nicht unterschieden. Die Veränderungen in der Verbreitung über mehrere Jahre hinweg hingen im Großen und Ganzen nicht von der Entfernung vom Verbreitungszentrum der betreffenden Art ab. Zeitliche Veränderungen im Vorkommen einer Art können in sehr feinem räumlichen Maßstab auftreten, aber die Ursache hierfür zu verstehen ist noch eine echte Herausforderung. Unsere Ergebnisse schließen eine Lücke in der Ökologieliteratur und haben möglicherweise wichtige Auswirkungen auf die Naturschutzplanung.

\section{Introduction}

The number of individuals of a species in a particular location is commonly referred to as abundance. Abundance often peaks at one or more places within a species' distribution and then declines towards the periphery of the distribution. Such "peak-and-tail" patterns of abundance (McGill and Collins 2003), and their possible causes, have received substantial attention in the literature (Brown 1984, 1995; Brown et al. 1995; Gaston 2003; McGill and Collins 2003). Abundance distributions must, at least in part, reflect the distribution of suitable habitat (Brown et al. 1995). For example, in an analysis of forest birds in eastern North America, Ricklefs (2013) demonstrated that synthetic variables related to climate and habitat characteristics of local sites were spatially structured and could, to varying degrees, predict the abundance of many of the species. Ricklefs (2013) also found that the variation in abundance not explained by climate and habitat showed spatial structure for some species, suggesting that other spatially structured processes may also influence abundance distributions.

Temporal variation in abundance can also be sizable (McGill 2008). Temporal changes in abundance (e.g., the difference between abundance from one year to another) may exhibit spatial structure if they are caused by spatially structured processes. For example, spatially structured trends in weather might drive changes in species abundance over time. Surprisingly, the spatial structure of changes in abundance has only rarely been evaluated. This under-explored aspect of ecology may be important not only for basic science, but also for determining the spatial scales at which to undertake conservation efforts.

Much of what is known regarding temporal patterns of abundance comes from studies of birds. This is primarily the result of data generated by government-organized citizen-science programs, such as the annual North American Breeding Bird Survey (BBS; https://www.pwrc.usgs.gov/ bbs/), which identify and count birds at sites spanning large geographic distances. For example, using BBS data on 59 species, Böhning-Gaese et al. (1994) found that the relationship between abundance and time varied among relatively large regions within the species' distributions. Link and Sauer (2002) estimated temporal trends in abundance of the Cerulean Warbler (Setophaga cerulea) at ten regions within its breeding distribution. They described negative trends in nine of the ten regions, but three of the nine regions with negative trends had credibility intervals that overlapped with zero, suggesting a degree of spatial heterogeneity in changes in abundance. Finally, in a study of three North American passerine species, Mehlman (1997) found that changes in abundance were greatest towards the edges of the species' distributions, presumably where they were less abundant and where habitat suitability was lower or perhaps more variable through time. Overall, these studies suggest some degree of heterogeneity in the temporal changes in abundance, although none of the studies estimated spatial structure explicitly.

Spatial structure in any variable can be measured by calculating a metric of spatial autocorrelation. Spatial autocorrelation results from values of a given variable being more similar (positive autocorrelation) or less similar (negative autocorrelation) than expected by chance at particular distances from one another, and often appears as patches or gradients across a landscape (Legendre 1993). Positive spatial autocorrelation has been detected in the abundance of North American bird species at distances up to approximately 200 km (Brown et al. 1995; Bahn and McGill 2007; Ricklefs 2013), but we are unaware of similar attempts to detect spatial autocorrelation in temporal changes in avian abundance.

Here we investigate the spatial structure of yearly changes in abundance of North American breeding birds. We calculated a metric of spatial autocorrelation for yearly differences in the logarithm of abundance. Using log-transformed data ensured that the magnitude of temporal change was not strongly influenced by the initial abundance (e.g., the difference between the abundance in a local area increasing from $10^{2}$ to $10^{3}$ individuals would be the same as that in another area where abundance increased from $10^{3}$ to $10^{4}$ individuals). This approach is equivalent to taking the logarithm of the ratio of population sizes from two time points. We then compared the spatial structure in change in abundance with the spatial structure of abundance itself. One would expect 
to find spatial structure in change in abundance if the drivers of change in abundance were themselves spatially structured at scales broader than individual routes. An absence of spatial structure in change in abundance would indicate either highly localized processes acting on change in abundance or stochastic effects. Assuming that abundance and change in abundance are controlled by spatially structured local conditions at scales broader than individual routes, one might expect migrant species, which are exposed to local conditions on the breeding grounds for only part of the year, to exhibit less spatial structure than resident species, which are exposed year-round. In the absence of such spatially structured local conditions, we would not expect to find differences between migrants and residents. Thus, we also compared the spatial structure of abundance and change in abundance between resident and migrant species. Finally, we tested whether abundance, change in abundance, and variation in abundance over time were related to the distance to the abundance-weighted center of species' distributions. We again expected to find such change if abundance and change/ variation in abundance are controlled by conditions that are spatially structured at scales broader than individual routes.

\section{Methods}

\section{Data}

We used count data from the North American Breeding Bird Survey (BBS; Pardieck et al. 2016), which is composed of several thousand roadside routes, each approximately $40 \mathrm{~km}$ (24.5 miles) long. Volunteer observers visit each of 50 evenly spaced stops along a route, and record all of the birds seen or heard in a $3-\mathrm{min}$ period within a $0.4-\mathrm{km}(0.25$ mile $)$ radius of the stop. The number of counted individuals of a particular species is typically summed across stops and used as a metric of species abundance, with units referred to as "number of individuals per route". Routes are surveyed one or more times during the breeding season, typically in June. We first selected BBS routes sampled in at least 12 years over the period 1990-2010. We restricted our analysis to routes that met BBS standards. We then selected species of land birds (excluding raptors and galliforms) that have a large proportion of their breeding distributions represented by the 2532 BBS routes (Fig. 1) we selected (authors' qualitative assessment), and that were recorded on at least 200 of those routes. The latter criterion had the effect of removing from the analysis species with highly restricted geographic distributions. This left us with 133 species and two pairs of subspecies (Online Resource 1). We defined the distribution of each species by analyzing data only from routes where at least one individual of the species was recorded in at least three separate years.

\section{Analysis}

We took the natural logarithm of the count of each species on a route plus 0.001 (to account for counts of zero) for every year the route was surveyed and used this as our metric of abundance. We also calculated average abundance at
Fig. 1 Starting coordinates of all 2532 Breeding Bird Survey routes used in this study

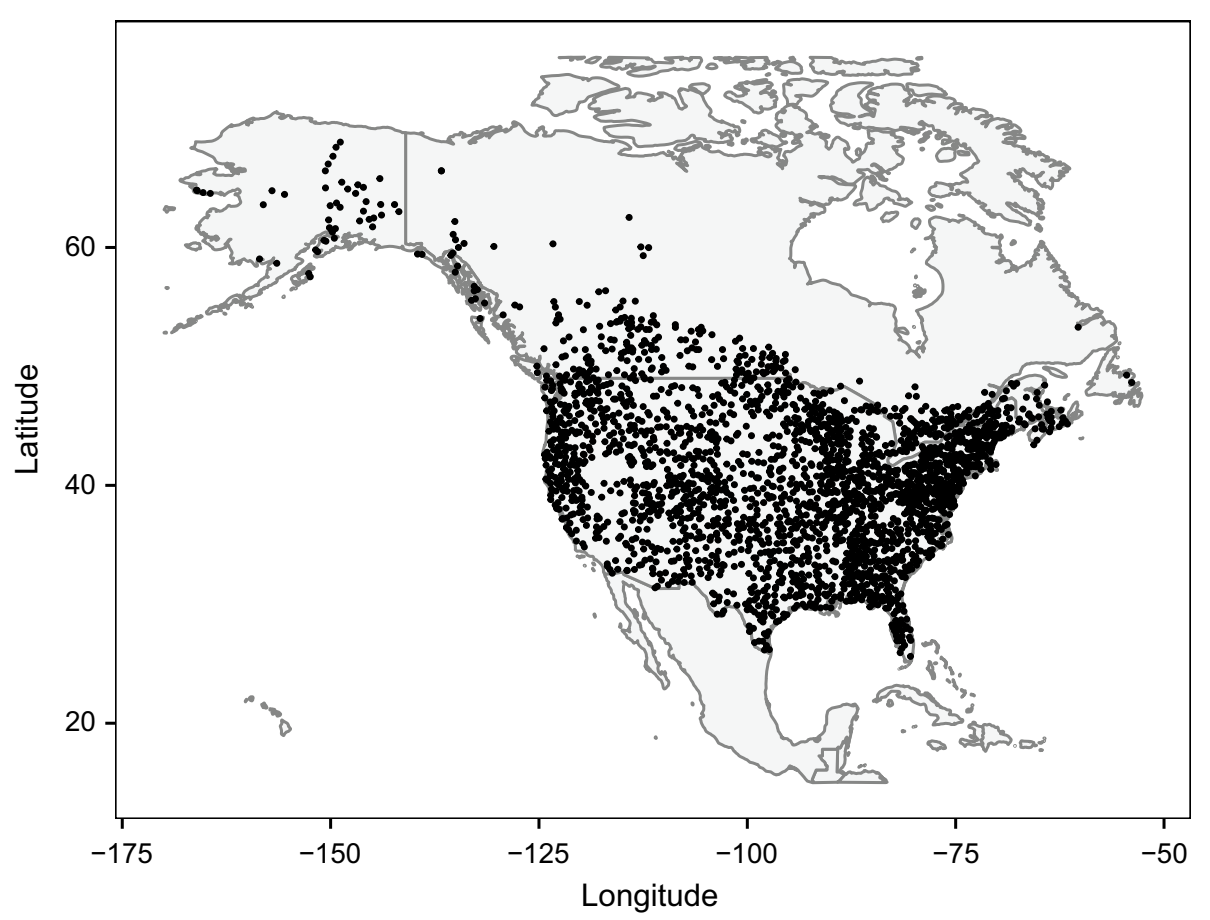


each route over the periods 1990-1995, 1990-2000, and 1990-2010. Averaging abundance over these three temporal windows is a rough way of controlling for observer-related errors and temporal stochasticity. We calculated the yearly change in abundance at each route as the difference between abundance $(\ln [$ count +0.001$])$ in year $t+1$ minus the abundance in year $t$. We did this for each of the one year intervals that a route was sampled. Change in abundance is often presented as the logarithm of abundance in year $t+1$ divided by the abundance in year $t$; this measure is equivalent to the metric we present here. We also calculated the change in abundance over three multi-year intervals-the difference in abundance between 1990 and 1995, 1990 and 2000, and 1990 and 2010. This was also done as an attempt to control for observer-related errors and temporal stochasticity; we hoped to capture change in abundance that might accumulate slowly, over intervals longer than 1 year. We also calculated the change in abundance between the average of the years 2005-2010 and the years 1990-1995. This was done by taking the natural $\log$ of the average count plus 0.001 at routes within each of the two multi-year intervals and then subtracting the 1990-1995 values from the 2005-2010 values. This was also an attempt to control for possible year-to-year stochasticity in the counts. As stated previously, log-transforming the data ensured that the magnitude of temporal change was not strongly influenced by initial abundance. The addition of a constant to each count will cause bias in the calculation of change in abundance for routes that have zero counts. Thus, any such constant should be small. Sauer et al. (1994) added 0.5 to BBS count data for a similar analysis involving the calculation of log-transformed change in abundance. We added a smaller constant (0.001) for this analysis.

We determined the degree of spatial autocorrelation in abundance and change in abundance for each species in each year or year-interval and across the three multi-year time periods to assess spatial structure. We used Moran's $I$ as a metric of spatial autocorrelation (Moran 1950). Moran's I is computed over multiple distance classes $(d)$ as:

$I(d)=\frac{n}{W} \frac{\sum_{h=1}^{n} \sum_{i=1}^{n} w_{h i}\left(y_{h}-\bar{y}\right)\left(y_{i}-\bar{y}\right)}{\sum_{i=1}^{n}\left(y_{i}-\bar{y}\right)^{2}}$

where $h$ and $i$ represent pairs of unique routes (i.e. $h \neq i$ ) of which there are $n$ total routes; $y_{h}$ and $y_{i}$ represent the variable of interest (abundance or change in abundance) at each of those routes, and $\bar{y}$ is the average of $y$ over all $n$ routes; $w_{h i}$ is a weight that equals 1 when the distance between routes $h$ and $i$ fall within the distance class $d$, and zero when it does not; $W$ is the number of pairs of routes in each distance class (Borcard and Legendre 2012). Positive values of $I$ indicate positive autocorrelation (pairs of routes within a given distance class are more similar than expected by chance) and negative values indicate negative autocorrelation (pairs of routes within a distance class are less similar than expected by chance) because the expected value for no spatial autocorrelation $([-1 /(n-1)]$; Borcard and Legendre 2012) approaches zero for large samples. We calculated Moran's $I$ using the function "correlog" in the R package ncf (Bjørnstad 2016), and we set the distance classes to equal increments of $100 \mathrm{~km}$. We used the starting coordinates of BBS routes to calculate distances.

We categorized species as either migrants or residents by examining their distribution maps (available on http://www. allaboutbirds.org); 22 species could not be categorized as either migrants or residents (i.e. they have populations that migrate and populations that do not within the study area) and were not included in the comparison (Online Resource 1). We compared Moran's I values of abundance (averaged over the period 1990-2010) and change in abundance (the difference between abundance in 1990 and 2010) between species in the migrant and resident groups at distance classes of 100, 200, and $300 \mathrm{~km}$ using two-tailed $t$ tests with Welch's correction for unequal variances.

We were also interested in correlating changes in abundance with distance to the abundance-weighted center of a species' distribution. To do this, we first calculated the centroid of the routes within a species' distribution weighted by the species' abundance $[\ln ($ count +0.001$)]$ averaged over the years each route was sampled. Thus, the abundance-weighted center of a distribution was defined by the abundance-weighted averages of the latitude and longitude of the routes within a species' distribution. The distance between each route and the center of the species' distribution was calculated with the function "rdist.earth" in the R package fields (Nychka et al. 2015). We calculated two indices of change in abundance at each route for each species over the three multi-year time periods mentioned previously. The first, which we call "proportional change", is the absolute value of the difference in abundance $[\ln$ (count $+0.001)$ ] between the years 1990 and 1995, 1990 and 2000, and 1990 and 2010. The second is the coefficient of variation (CV) of abundance among the years within each of the three multi-year periods [standard deviation of $\ln$ (count $+0.001)$ divided by the mean of $\ln ($ count +0.001$)]$. These metrics differ in that $\mathrm{CV}$ measures variation in abundance among years in the multi-year interval while also controlling for average abundance, whereas the proportional change metric quantifies the change from the first to the last year of the multi-year period and is not influenced by average abundance. Finally, we related the distance from each route to the abundance-weighted center of a species' distribution with each of the two indices of change in abundance using the non-parametric Spearman's correlation $\left(r_{\mathrm{s}}\right)$. The log-transformation of abundance to calculate the centroids of the species distributions and the variation in abundance 
through time were used to make the analysis consistent with the previously described Moran's I analysis. We also present the same analysis without $\log$-transforming abundance (i.e., centroids and coefficients of variation in abundance were calculated with raw count data) for comparison. One might not expect a relationship between change in abundance and the distance to the center of species' distributions if there is no relationship between abundance itself and the distance to the center of species' distributions. Therefore, we also show the relationship for abundance. We calculated the log of the average of species counts plus 0.001 at each route within the three multi-year intervals and tested for a correlation with distance to the center of the species distribution as before; the results are presented with the change in abundance results.

All statistical operations were performed in R v.3.3.0 ( $\mathrm{R}$ Core Team 2016).

\section{Results}

Similar to previous studies, we found positive spatial autocorrelation in abundance at distances up to a few hundred kilometers in the majority of species we investigated
(Table 1; Fig. 2; Online Resource 2). However, we found relatively weak to no spatial autocorrelation in change in abundance over the same distances (Table 2; Fig. 3; Online Resource 2). This lack of spatial structure was observed even over decadal periods (1990-2000 and 1990-2010), which were chosen to minimize the impact of observer error and temporal stochasticity. However, the difference between the average of abundance over the 1990-1995 period and the 2005-2010 period showed greater spatial structure than the changes in abundance between single years (Fig. 4). Nevertheless, even this change in abundance had lower spatial structure than abundance itself, with the majority of species (125 of 135) having Moran's $I$ below 0.2 in the first $100-\mathrm{km}$ distance class. These results of abundance having greater spatial structure than change in abundance were largely consistent across species, even readily detected species like the Northern Cardinal (Cardinalis cardinalis; Fig. 5), the detectability of which should be less impacted by observer skill than rarer species or species with drabber plumage or less distinctive vocalizations. However, Fig. 2 reveals that one species, the Lark Bunting (Calamospiza melanocorys), had noticeably higher spatial structure in change in abundance than the other species (mean Moran's I of 0.277 at the 100-km
Table 1 Moran's $I$ of abundance $[\ln ($ count +0.001$)]$ at three distance classes $(100,200$, $300 \mathrm{~km}$ ) averaged over all species in each year of the study and using average abundance over the three multi-year periods

\begin{tabular}{|c|c|c|c|}
\hline \multirow[t]{2}{*}{ Year } & \multicolumn{3}{|c|}{ Moran's I (mean \pm SE) } \\
\hline & $100 \mathrm{~km}$ & $200 \mathrm{~km}$ & $300 \mathrm{~km}$ \\
\hline 1990 & $0.2052 \pm 0.0112$ & $0.1374 \pm 0.0092$ & $0.0983 \pm 0.0079$ \\
\hline 1991 & $0.2069 \pm 0.0107$ & $0.1403 \pm 0.0087$ & $0.0941 \pm 0.0079$ \\
\hline 1992 & $0.2023 \pm 0.0094$ & $0.1335 \pm 0.0085$ & $0.0956 \pm 0.0074$ \\
\hline 1993 & $0.2029 \pm 0.0091$ & $0.1359 \pm 0.0080$ & $0.0934 \pm 0.0072$ \\
\hline 1994 & $0.1981 \pm 0.0091$ & $0.1357 \pm 0.0078$ & $0.0950 \pm 0.0069$ \\
\hline 1995 & $0.1964 \pm 0.0088$ & $0.1277 \pm 0.0078$ & $0.0912 \pm 0.0066$ \\
\hline 1996 & $0.1953 \pm 0.0096$ & $0.1295 \pm 0.0081$ & $0.0950 \pm 0.0067$ \\
\hline 1997 & $0.1955 \pm 0.0089$ & $0.1344 \pm 0.0076$ & $0.0932 \pm 0.0068$ \\
\hline 1998 & $0.1928 \pm 0.0093$ & $0.1324 \pm 0.0083$ & $0.0925 \pm 0.0067$ \\
\hline 1999 & $0.1954 \pm 0.0085$ & $0.1287 \pm 0.0074$ & $0.0910 \pm 0.0064$ \\
\hline 2000 & $0.1869 \pm 0.0083$ & $0.1236 \pm 0.0077$ & $0.0905 \pm 0.0065$ \\
\hline 2001 & $0.1944 \pm 0.0090$ & $0.1273 \pm 0.0080$ & $0.0947 \pm 0.0064$ \\
\hline 2002 & $0.1991 \pm 0.0086$ & $0.1337 \pm 0.0078$ & $0.0961 \pm 0.0064$ \\
\hline 2003 & $0.1944 \pm 0.0088$ & $0.1266 \pm 0.0079$ & $0.0961 \pm 0.0063$ \\
\hline 2004 & $0.1960 \pm 0.0082$ & $0.1328 \pm 0.0072$ & $0.0951 \pm 0.0061$ \\
\hline 2005 & $0.1904 \pm 0.0089$ & $0.1319 \pm 0.0074$ & $0.0946 \pm 0.0064$ \\
\hline 2006 & $0.1952 \pm 0.0091$ & $0.1296 \pm 0.0074$ & $0.0930 \pm 0.0064$ \\
\hline 2007 & $0.2024 \pm 0.0092$ & $0.1356 \pm 0.0077$ & $0.0923 \pm 0.0068$ \\
\hline 2008 & $0.2054 \pm 0.0091$ & $0.1380 \pm 0.0081$ & $0.1018 \pm 0.0069$ \\
\hline 2009 & $0.2086 \pm 0.0091$ & $0.1374 \pm 0.0079$ & $0.0972 \pm 0.0067$ \\
\hline 2010 & $0.2101 \pm 0.0094$ & $0.1392 \pm 0.0082$ & $0.0964 \pm 0.0068$ \\
\hline Average 1990 to 1995 & $0.2871 \pm 0.0104$ & $0.1938 \pm 0.0100$ & $0.1362 \pm 0.0091$ \\
\hline Average 1990 to 2000 & $0.3117 \pm 0.0105$ & $0.2104 \pm 0.0102$ & $0.1467 \pm 0.0094$ \\
\hline Average 1990 to 2010 & $0.3448 \pm 0.0103$ & $0.2311 \pm 0.0102$ & $0.1629 \pm 0.0094$ \\
\hline
\end{tabular}




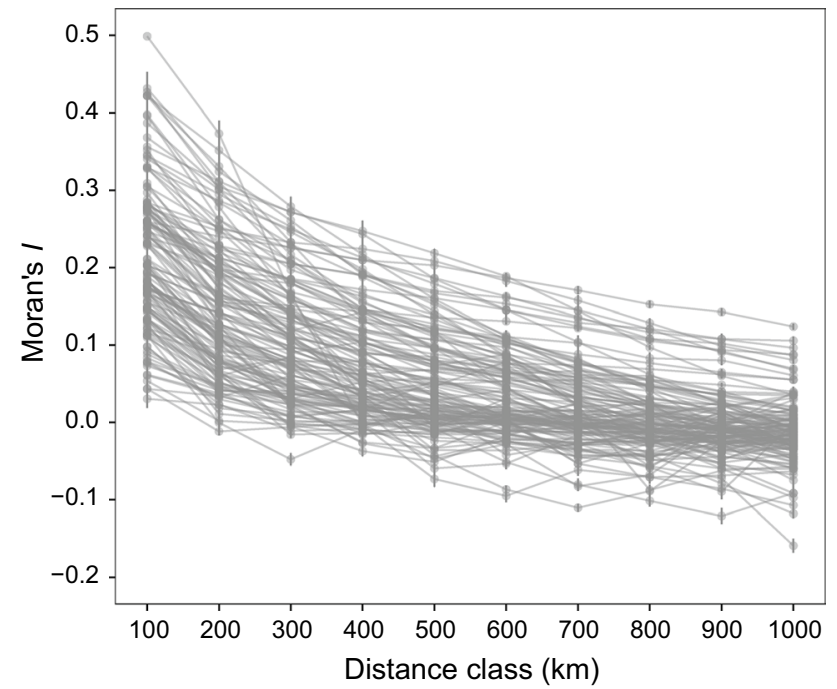

Fig. 2 Moran's $I$ of abundance $[\ln ($ count +0.001$)]$ at ten distance classes $(100-1000 \mathrm{~km})$. Each species in the analysis is represented by a separate line that follows the mean of Moran's I over the period 1990-2010. Error bars around the means represent standard errors

distance class). It is difficult to know why this species had such high spatial structure in change in abundance compared with other species, but it could have to do with spatially structured habitat loss that has led to recent declines (Schipper et al. 2016).

Migrants and residents exhibited similar spatial structure in abundance at distances of $100 \mathrm{~km}$, but migrants exhibited less spatial structure than residents at distances of 200 and $300 \mathrm{~km}$ (Table 3). Migrants and residents did not differ in spatial structure of change in abundance over the same three distance classes (Table 3).

Correlations between the proportional change in abundance and the distance to the abundance-weighted center of species' distributions were essentially zero (Table 4). Similarly, average correlations between CV of abundance using log-transformed count data and distance to the abundance-weighted center of species' distributions were close to zero. Using raw count data, correlations between distance to the centroid and CV were slightly higher (Table 4). The $P$ values of these correlations were strongly right-skewed within each of the three temporal windows (i.e., many of the $P$ values were small). Applying a Bonferroni correction to these correlations within each temporal window would result in a corrected alpha value of $0.00036(0.05 / 137$ species or subspecies). Examination of the largest temporal window (1990-2010) reveals that of the correlations between proportional change and distance to the center of the species' distributions, 20 had $P$ values below 0.00036 , and 18 were
Table 2 Moran's I of change in abundance at three distance classes $(100,200,300 \mathrm{~km})$ averaged over all species in each year interval of the study and over three multi-year periods

\begin{tabular}{|c|c|c|c|}
\hline \multirow[t]{2}{*}{ Year } & \multicolumn{3}{|c|}{ Moran's $I($ mean \pm SE $)$} \\
\hline & $100 \mathrm{~km}$ & $200 \mathrm{~km}$ & $300 \mathrm{~km}$ \\
\hline 1990 to 1991 & $0.0057 \pm 0.0049$ & $-0.0033 \pm 0.0029$ & $-0.0017 \pm 0.0023$ \\
\hline 1991 to 1992 & $0.0101 \pm 0.0063$ & $0.0064 \pm 0.0029$ & $9 e-04 \pm 0.0028$ \\
\hline 1992 to 1993 & $0.0175 \pm 0.0052$ & $0.0040 \pm 0.0030$ & $8 e-04 \pm 0.0024$ \\
\hline 1993 to 1994 & $0.0124 \pm 0.0048$ & $0.0030 \pm 0.0032$ & $5 e-04 \pm 0.0023$ \\
\hline 1994 to 1995 & $0.0101 \pm 0.0044$ & $0.0063 \pm 0.0029$ & $0.0041 \pm 0.0022$ \\
\hline 1995 to 1996 & $0.0119 \pm 0.0049$ & $0.0025 \pm 0.0026$ & $0.0022 \pm 0.0020$ \\
\hline 1996 to 1997 & $0.0175 \pm 0.0047$ & $0.0063 \pm 0.0033$ & $0.0088 \pm 0.0026$ \\
\hline 1997 to 1998 & $0.0101 \pm 0.0037$ & $0.0082 \pm 0.0029$ & $0.0052 \pm 0.0025$ \\
\hline 1998 to 1999 & $0.0070 \pm 0.0034$ & $0.0011 \pm 0.0023$ & $0.0021 \pm 0.0017$ \\
\hline 1999 to 2000 & $0.0112 \pm 0.0038$ & $0.0064 \pm 0.0028$ & $0.0038 \pm 0.0018$ \\
\hline 2000 to 2001 & $0.0184 \pm 0.0053$ & $0.0078 \pm 0.0045$ & $0.0059 \pm 0.0030$ \\
\hline 2001 to 2002 & $0.0100 \pm 0.0055$ & $0.0058 \pm 0.0036$ & $0.0028 \pm 0.0025$ \\
\hline 2002 to 2003 & $0.0118 \pm 0.0032$ & $-8 \mathrm{e}-04 \pm 0.0026$ & $0.0027 \pm 0.0018$ \\
\hline 2003 to 2004 & $0.0025 \pm 0.0034$ & $0.0044 \pm 0.0023$ & $0.0042 \pm 0.0017$ \\
\hline 2004 to 2005 & $0.0082 \pm 0.0036$ & $0.0051 \pm 0.0025$ & $6 e-04 \pm 0.0015$ \\
\hline 2005 to 2006 & $0.0103 \pm 0.0057$ & $0.0059 \pm 0.0035$ & $0.0051 \pm 0.0023$ \\
\hline 2006 to 2007 & $0.0076 \pm 0.0047$ & $-0.0015 \pm 0.0029$ & $0.0074 \pm 0.0024$ \\
\hline 2007 to 2008 & $0.0116 \pm 0.0045$ & $0.0054 \pm 0.0030$ & $0.0035 \pm 0.0024$ \\
\hline 2008 to 2009 & $0.0034 \pm 0.0034$ & $0.0000 \pm 0.0024$ & $7 e-04 \pm 0.0019$ \\
\hline 2009 to 2010 & $0.0076 \pm 0.0038$ & $0.0024 \pm 0.0021$ & $0.0015 \pm 0.0018$ \\
\hline 1990 to 1995 & $0.0314 \pm 0.0064$ & $0.0088 \pm 0.0043$ & $0.0083 \pm 0.0035$ \\
\hline 1990 to 2000 & $0.0466 \pm 0.0068$ & $0.0186 \pm 0.0048$ & $0.0192 \pm 0.0039$ \\
\hline 1990 to 2010 & $0.0897 \pm 0.0097$ & $0.0525 \pm 0.0062$ & $0.0280 \pm 0.0052$ \\
\hline
\end{tabular}




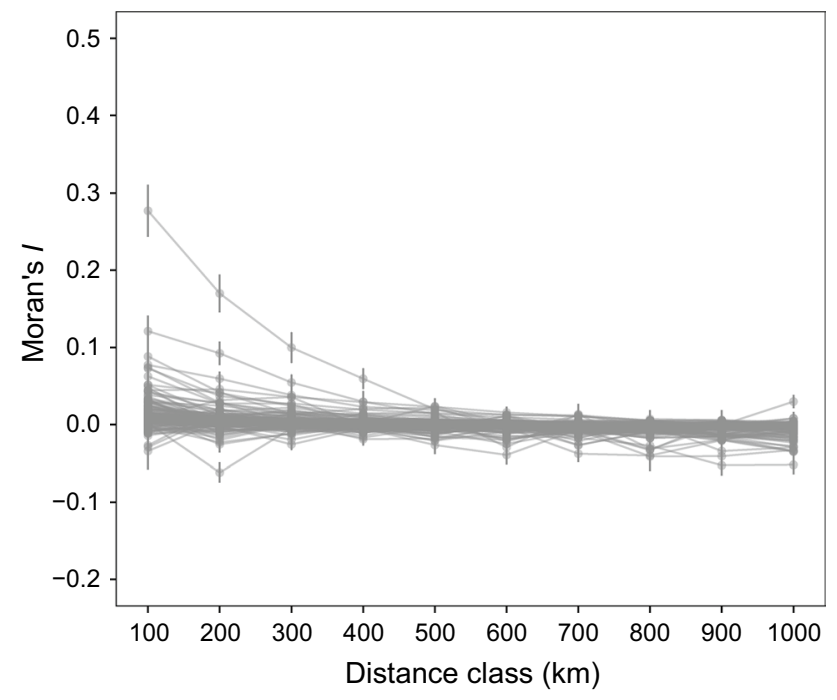

Fig. 3 Moran's $I$ of yearly change in abundance at ten distance classes $(100-1000 \mathrm{~km})$. Each species in the analysis is represented by a separate line that follows the mean of Moran's $I$ over the yearly intervals from 1990 to 2010. Error bars around the means represent standard errors

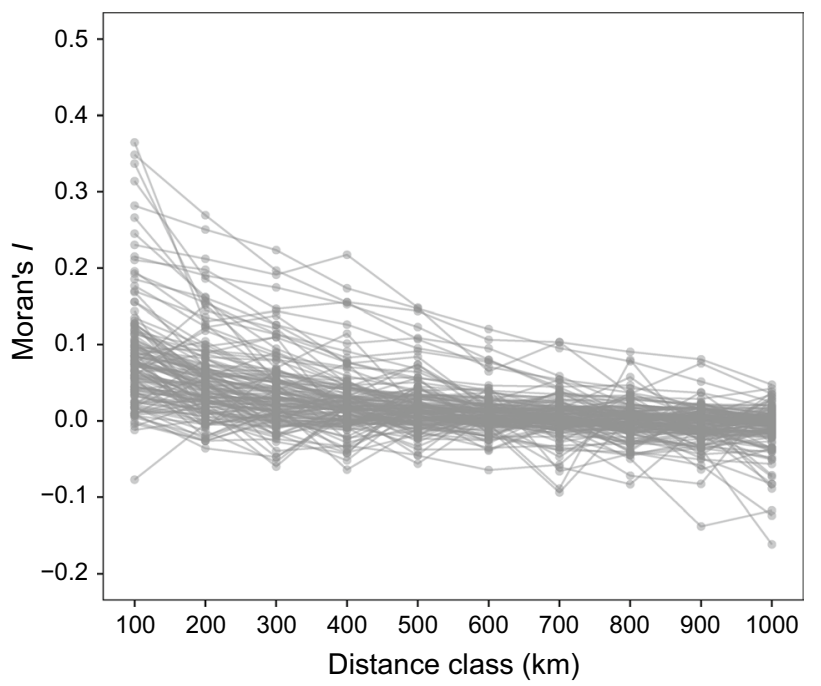

Fig. 4 Moran's $I$ of the difference between abundance averaged over two multi-year periods, 2005-2010 and 1990-1995, calculated at ten distance classes (100-1000 km). Each species in the analysis is represented by a separate line

positive correlations. For correlations with log-transformed CV, 49 had $P$ values below 0.00036 ; of those correlations, 29 were positive and 20 were negative. Correlations with untransformed CV were stronger (Table 4) and included 88 with $P$ values below 0.00036 ; of those correlations, 86 were positive and only two were negative. Correlations between abundance itself and the distance to the center of species distributions were also close to zero (Table 4). All
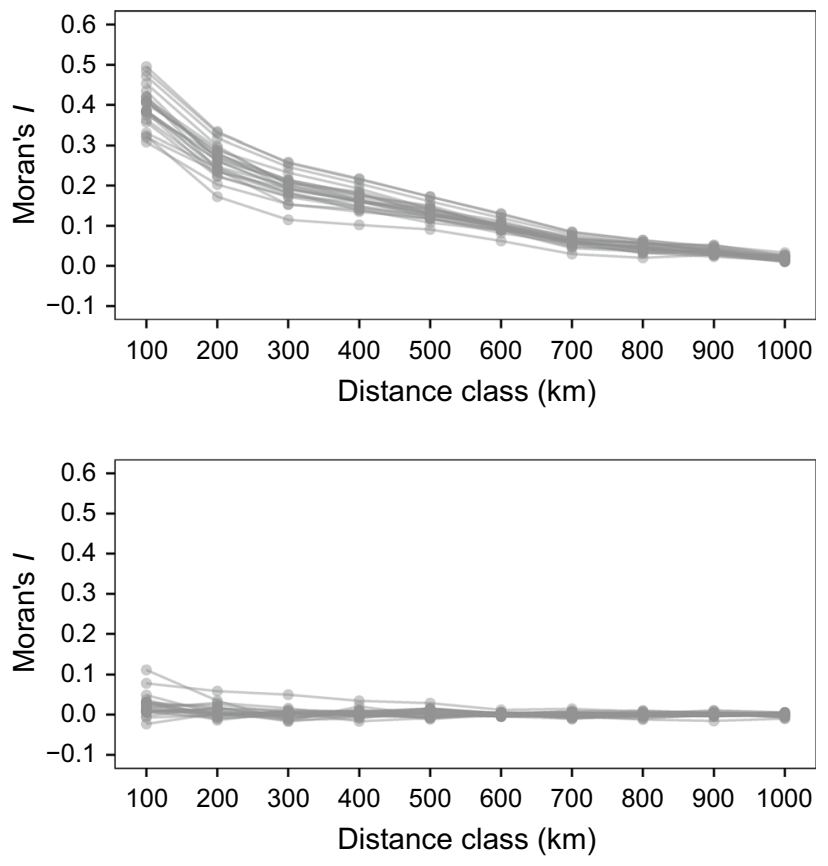

Fig. 5 Top graphic: Moran's $I$ of abundance $[\ln (\operatorname{count}+0.001)]$ at ten distance classes $(100-1000 \mathrm{~km})$ for the Northern Cardinal (Cardinalis cardinalis). Each line represents a 1-year period from 1990 to 2010. Bottom graphic: Moran's $I$ of yearly change in abundance for the Northern Cardinal. Lines represent each 1-year period from 1990 to 2010

species-specific correlations within each of the three temporal windows can be found in Online Resource 3.

\section{Discussion}

Yearly and decadal changes in breeding season abundance exhibited little spatial structure over distances as small as $100 \mathrm{~km}$ in most bird species we investigated (Table 2), in stark contrast to abundance itself (Table 1). Spatial structure increased when change in abundance was calculated between multi-year averages (Fig. 4), but was still lower than the spatial structure of abundance itself in any given year. Spatial heterogeneity in the temporal changes of avian abundance has been found previously, but over much broader spatial scales. For example, temporal trends in avian abundance are often estimated for Bird Conservation Regions (BCRs), which are large areas designed to facilitate avian conservation in North America, many stretching hundreds of kilometers. Wilson et al. (2011) found that the breeding season abundance of American Redstarts (Setophaga ruticilla) decreased in several BCRs in the United States and increased in others over the period 1982-2007. Similarly, a study of American Black Ducks (Anas rubripes) found that trends in winter abundance varied among BCRs over the 
Table 3 Results of $t$ tests comparing values of Moran's I in abundance (averaged over the period 1990-2010) and change in abundance (the difference in abundance between the years 1990 and 2010) at three distance classes between migrant and resident species

\begin{tabular}{llll}
\hline & $100 \mathrm{~km}$ & $200 \mathrm{~km}$ & $300 \mathrm{~km}$ \\
\hline Abundance & & & \\
Resident Moran's $I$ & $0.359 \pm 0.023$ & $0.262 \pm 0.020$ & $0.196 \pm 0.019$ \\
Migrant Moran's $I$ & $0.332 \pm 0.014$ & $0.212 \pm 0.013$ & $0.140 \pm 0.012$ \\
& $t_{57.05}=1.04, P=0.300$ & $t_{62.48}=2.08, P=0.042$ & $t_{59.60}=2.48, P=0.016$ \\
Change in abundance & & $0.057 \pm 0.015$ & $0.037 \pm 0.011$ \\
Resident Moran's $I$ & $0.082 \pm 0.021$ & $0.046 \pm 0.007$ & $0.023 \pm 0.006$ \\
Migrant Moran's $I$ & $0.084 \pm 0.011$ & $t_{45.23}=0.67, P=0.509$ & $t_{52.37}=1.15, P=0.256$ \\
\hline
\end{tabular}

Means and standard errors for Moran's $I$ are shown for each group. Residents had higher Moran's $I$ values than migrants for abundance at the 200- and 300-km distance classes. Degrees of freedom adjusted for unequal variances between groups using Welch's approximation

Table 4 Correlation coefficients (Spearman's $r_{\mathrm{s}}$ ) averaged over all species for the relationship between change in abundance and geographic distance to the center of species distributions

\begin{tabular}{lllll}
\hline Years & $\mathrm{Ab}$ & PC- $t$ & $\mathrm{CV}-t$ & $\mathrm{CV}$ \\
\hline 1990 to 1995 & $0.018 \pm 0.016(0.117 \pm 0.019)$ & $0.020 \pm 0.008(0.350 \pm 0.027)$ & $0.006 \pm 0.011(0.235 \pm 0.025)$ & $0.170 \pm 0.014(0.141 \pm 0.022)$ \\
1990 to 2000 & $0.010 \pm 0.017(0.130 \pm 0.022)$ & $0.026 \pm 0.009(0.307 \pm 0.027)$ & $0.008 \pm 0.011(0.222 \pm 0.025)$ & $0.206 \pm 0.015(0.074 \pm 0.015)$ \\
1990 to 2010 & $-0.008 \pm 0.019(0.153 \pm 0.023)$ & $0.018 \pm 0.011(0.322 \pm 0.027)$ & $0.009 \pm 0.011(0.162 \pm 0.021)$ & $0.235 \pm 0.015(0.066 \pm 0.016)$ \\
\hline
\end{tabular}

Change in abundance was calculated in two ways. Proportional change transformed (PC- $t$ ) is the absolute value of the difference in the $\ln [$ count +0.001 ] between the years 1990 and 1995, 1990 and 2000, and 1990 and 2010; coefficient of variation transformed (CV-t) was calculated using the $\ln [$ count +0.001$]$ in each year over the same three time periods. We also present the relationships between geographic distance and untransformed coefficient of variation (CV; i.e., untransformed count data were used in the calculation of $\mathrm{CV}$ and in the calculation of the center of the species' distribution). The relationship between average abundance (Ab) over each multi-year period and distance to center of species distributions is also presented. Means and standard errors of Spearman's $r_{\mathrm{s}}$ are presented, and means and standard errors of associated $P$ values are presented in parentheses. Individual correlations can be found in Online Resource 3

period 1996-2003 (Link et al. 2006). Ricklefs (1989) averaged BBS route data within states for the American Robin (Turdus migratorius) and, using a principal components analysis, revealed three large regions that changed in abundance independently of one another over a 14-year period. Our analysis suggests that there is likely substantial variation in temporal changes in abundance within BCRs, and within other large regions as well.

It is unlikely that the low spatial structure in change in abundance that we report is due solely to observer effects (i.e., differences in observer skill leading to errors in estimation of abundance). First, substantial spatial structure was found for abundance within years, even though that analysis involved comparing the data from routes that were visited by different observers. Second, the analysis holds for readily detectable birds like the Northern Cardinal (Fig. 5), for which estimates should be most robust to differences in observer skill. Finally, we re-ran the analysis after removing observers' first times recording any particular route (an observer's first time recording a route is probably their least accurate [Kendall et al. 1996]) and the results held (Online Resource 4). Because of this, we suspect that the low spatial structure in change in abundance is a real phenomenon.
We also found that the spatial structure of abundance is greater in resident species than migrant species at distances of 200 and $300 \mathrm{~km}$ (Table 3). This result is consistent with local factors (e.g., weather and habitat on the breeding grounds) driving the spatial structure of abundance, since residents are exposed to local conditions year-round, while migrants are exposed to local conditions for only part of the year. Nevertheless, the spatial structure of change in abundance did not differ between migrant and resident species; both groups had equally low spatial structure. This lack of spatial structure suggests that the drivers of changes in local abundance occur at scales smaller than individuals routes for both migrant and resident species.

Similar to temporal changes in abundance, which showed little spatial structure, variation in abundance over three multi-year periods was mostly unrelated to distance from the abundance-weighted center of each species' distribution (Table 4). This result makes sense given that we also found a lack of consistent relationships between abundance itself and distance to the center of species' distributions (Table 4). However, some correlations were significant even after a Bonferroni correction, and the majority of these were positive correlations (Online Resource 3). A frequently cited 
hypothesis in ecology suggests that populations at the edges of a species' distribution are more variable over time than those near the center of the distribution (Sagarin and Gaines 2002). Curnutt et al. (1996) found support for this hypothesis from nine species of sparrows in North America analyzed using BBS count data collected from 1967 to 1989. They suggested that populations at the edges of the species' distributions are sinks (i.e., reproduction is insufficient to compensate for mortality), which are repopulated by source populations with relatively high abundance located in the center of the species' distributions. However, the relationships between variation in abundance and distance from the center of the distribution were generally weak in the analysis by Curnutt et al. (1996); source-sink dynamics involving central and edge populations cannot explain the majority of the variation in temporal abundance dynamics. Our analysis revealed many instances of no relationship between variation in abundance over time and distance to the center of a species' range. The few significant relationships we did find were mostly positive, but did not explain much of the variation in the data (Online Resource 3).

Many factors can influence avian population size, including nest predation (Sherry et al. 2015), parasitism (LaDeau et al. 2007; Ricklefs et al. 2016), both natural (Holmes and Sherry 2001) and human-caused (Schmiegelow and Mönkkönen 2002) habitat changes, and food availability (Arcese and Smith 1988; Rodenhouse and Holmes 1992; Barber et al. 2008), the latter often mediated by changes in climate (Sillett et al. 2000). Some of these factors are likely spatially structured. For example, decadal trends in temperature and precipitation, which may impact avian food availability, vary regionally across the continental United States (Portmann et al. 2009). Such spatially structured processes may be able to explain regional trends in abundance over time (Gorzo et al. 2016), but they cannot explain the fine-scale changes in abundance that we describe here.

Fine-scale temporal changes in abundance could be the result of stochastic processes acting across species distributions or of deterministic processes acting independently at scales smaller than $100 \mathrm{~km}$. Stochastic population processes can include demographic stochasticity (chance changes in individual probabilities of reproduction or mortality), environmental stochasticity (chance changes in the environment that change the probability of reproduction or mortality of all individuals), and random catastrophes (reductions in population size due to chance changes in the environment); the first is important mostly for small populations, while the latter two affect both large and small populations (Lande 1993). Demographic stochasticity may be involved in determining the higher variation in abundance of peripheral populations, which tend to be smaller (Curnutt et al. 1996). The importance of environmental stochasticity and random catastrophes to the fine-scale changes in abundance is difficult to evaluate for lack of data. Nevertheless, extreme winters have been shown to reduce avian population sizes, with reductions often proportionally greater in edge populations (Mehlman 1997). Importantly, it is easy to imagine environmental stochasticity and random catastrophes as potentially being spatially structured at scales greater than individual routes, and it is difficult to imagine demographic stochasticity playing a role across the entire distributions of the species investigated.

Ricklefs (2013) showed that the spatial variation in abundance of several species of North American forest birds not explained by habitat and climate was spatially structured at distances of less than $100 \mathrm{~km}$. The species-specific nature of these abundance anomalies led Ricklefs (2013) to posit that they were the result of specialized pathogens. Indeed, several lines of evidence suggest that pathogens may strongly influence species abundance and distribution (van Riper et al. 1986; Mangan et al. 2010; Ricklefs 2015; Ricklefs et al. 2016; Ellis et al. 2017). Whether localized pathogens and parasites contribute to the fine-scale changes in abundance documented here is unknown, but should be explored in future studies.

While temporal trends in abundance are detectable at broad spatial scales, temporal changes in abundance may also occur at fine scales. Such fine-scale changes in abundance are often ignored, even though our analysis shows them to be the rule rather than the exception. The causes of such fine-scale temporal changes in abundance are largely unknown and require investigation. Besides adding to basic ecological theory, a focus on fine-scale changes in abundance may also be important for effective conservation planning, which requires understanding threats to species at multiple spatial scales (Whited et al. 2000; Faaborg et al. 2010).

Acknowledgements This work would not have been possible without the thousands of people who perform and coordinate the North American Breeding Birds Survey every year and the people who curate and maintain the data online. We thank Robert E. Ricklefs and several anonymous reviewers for providing insightful feedback on earlier versions of the manuscript. V.A.E. was supported by a CAPES PNPD postdoctoral fellowship from Brazil.

Open Access This article is distributed under the terms of the Creative Commons Attribution 4.0 International License (http://creativeco mmons.org/licenses/by/4.0/), which permits unrestricted use, distribution, and reproduction in any medium, provided you give appropriate credit to the original author(s) and the source, provide a link to the Creative Commons license, and indicate if changes were made.

\section{References}

Arcese P, Smith JNM (1988) Effects of population density and supplemental food on reproduction in song sparrows. J Anim Ecol 57:119-136. https://doi.org/10.2307/4768 
Bahn V, McGill BJ (2007) Can niche-based distribution models outperform spatial interpolation? Glob Ecol Biogeogr 16:733-742. https://doi.org/10.1111/j.1466-8238.2007.00331.x

Barber NA, Marquis RJ, Tori WP (2008) Invasive prey impacts the abundance and distribution of native predators. Ecology $89: 2678-2683$

Bjørnstad ON (2016) ncf: spatial nonparametric covariance functions. $\mathrm{R}$ package version 1.2-1. https://CRAN.R-project.org/packa ge $=$ ncf

Böhning-Gaese K, Taper ML, Brown JH (1994) Avian community dynamics are discordant in space and time. Oikos 70:121-126

Borcard D, Legendre P (2012) Is the Mantel correlogram powerful enough to be useful in ecological analysis? A simulation study. Ecology 93:1473-1481

Brown JH (1984) On the relationship between abundance and distribution of species. Am Nat 124:255-279

Brown JH (1995) Macroecology. The University of Chicago Press, Chicago

Brown JH, Mehlman DW, Stevens GC (1995) Spatial variation in abundance. Ecology 76:2028-2043. https://doi.org/10.2307/1941678

Curnutt JL, Pimm SL, Maurer BA (1996) Population variability of sparrows in space and time. Oikos 76:131-144. https://doi. org/10.2307/3545755

Ellis VA, Medeiros MCI, Collins MD et al (2017) Prevalence of avian haemosporidian parasites is positively related to the abundance of host species at multiple sites within a region. Parasitol Res 116:73-80. https://doi.org/10.1007/s00436-016-5263-3

Faaborg J, Holmes RT, Anders AD et al (2010) Conserving migratory land birds in the New World: do we know enough? Ecol Appl 20:398-418

Gaston KJ (2003) The structure and dynamics of geographic ranges. Oxford University Press, Oxford

Gorzo JM, Pidgeon AM, Thogmartin WE et al (2016) Using the North American Breeding Bird Survey to assess broad-scale response of the continent's most imperiled avian community, grassland birds, to weather variability. Condor 118:502-512. https://doi. org/10.1650/CONDOR-15-180.1

Holmes RT, Sherry TW (2001) Thirty-year bird population trends in an unfragmented temperate deciduous forest: importance of habitat change. Auk 118:589-609

Kendall WL, Peterjohn BG, Sauer JR (1996) First-time observer effects in the North American Breeding Bird Survey. Auk 113:823-829. https://doi.org/10.2307/4088860

LaDeau SL, Kilpatrick AM, Marra PP (2007) West Nile virus emergence and large-scale declines of North American bird populations. Nature 447:710-713. https://doi.org/10.1038/nature05829

Lande R (1993) Risks of population extinction from demographic and environmental stocasticity and random catastrophes. Am Nat 142:911-927

Legendre P (1993) Spatial autocorrelation: trouble or new paradigm? Ecology 74:1659-1673. https://doi.org/10.2307/1939924

Link WA, Sauer JR (2002) A hierarchical analysis of population change with application to cerulean warblers. Ecology 83:2832. https:// doi.org/10.2307/3072019

Link WA, Sauer JR, Niven DK (2006) A hierarchical model for regional analysis of population change using Christmas Bird Count data, with application to the American Black Duck. Condor 108:13-24

Mangan SA, Schnitzer SA, Herre EA et al (2010) Negative plant-soil feedback predicts tree-species relative abundance in a tropical forest. Nature 466:752-755. https://doi.org/10.1038/nature09273

McGill BJ (2008) Exploring predictions of abundance from body mass using hierarchical comparative approaches. Am Nat 172:88-101. https://doi.org/10.1086/588044
McGill B, Collins C (2003) A unified theory for macroecology based on spatial patterns of abundance. Evol Ecol Res 5:469-492

Mehlman DW (1997) Change in avian abundance across the geographic range in response to environmental change. Ecol Appl 7:614. https ://doi.org/10.2307/2269525

Moran PAP (1950) Notes on continuous stochastic phenomena. Biometrika 37:17. https://doi.org/10.2307/2332142

Nychka D, Furrer R, Paige J, Sain S (2015) Fields: tools for spatial data. Boulder, CO, USA

Pardieck KL, Ziolkowski Jr. DJ, Hudson M-AR, Campbell K (2016) North American Breeding Bird Survey dataset 1966-2015, version 2015.0

Portmann RW, Solomon S, Hegerl GC (2009) Spatial and seasonal patterns in climate change, temperatures, and precipitation across the United States. Proc Natl Acad Sci 106:7324-7329

R Core Team (2016) R: a language and environment for statistical computing. R Foundation for Statistical Computing, Vienna

Ricklefs RE (1989) Spatial and temporal patterns and processes in communities of forest birds. Ostrich 60:85-95. https://doi. org/10.1080/00306525.1989.9639623

Ricklefs RE (2013) Habitat-independent spatial structure in populations of some forest birds in eastern North America. J Anim Ecol 82:145-154. https://doi.org/10.1111/j.1365-2656.2012.02024.x

Ricklefs RE (2015) Intrinsic dynamics of the regional community. Ecol Lett 18:497-503. https://doi.org/10.1111/ele.12431

Ricklefs RE, Soares L, Ellis VA, Latta SC (2016) Haemosporidian parasites and avian host population abundance in the Lesser Antilles. J Biogeogr 43:1277-1286. https://doi.org/10.1111/jbi.12730

Rodenhouse NL, Holmes RT (1992) Results of experimental and natural food reductions for breeding black-throated blue warblers. Ecology 73:357-372. https://doi.org/10.2307/1938747

Sagarin RD, Gaines SD (2002) The "abundant centre" distribution: to what extent is it a biogeographical rule? Ecol Lett 5:137-147

Sauer JR, Peterjohn BG, Link WA (1994) Observer differences in the North American Breeding Bird Survey. Auk 111:50-62. https:// doi.org/10.2307/4088504

Schipper AM, Belmaker J, de Miranda MD et al (2016) Contrasting changes in the abundance and diversity of North American bird assemblages from 1971 to 2010. Glob Change Biol 22:39483959. https://doi.org/10.1111/gcb.13292

Schmiegelow FKA, Mönkkönen M (2002) Habitat loss and fragmentation in dynamic landscapes: avian perspectives from the boreal forest. Ecol Appl 12:375-389. https://doi.org/10.2307/3060949

Sherry TW, Wilson S, Hunter S, Holmes RT (2015) Impacts of nest predators and weather on reproductive success and population limitation in a long-distance migratory songbird. J Avian Biol 46:559-569. https://doi.org/10.1111/jav.00536

Sillett TS, Holmes RT, Sherry TW (2000) Impacts of a global climate cycle on population dynamics of a migratory songbird. Science 288:2040-2042

van Riper IIIC, van Riper SG, Goff ML, Laird M (1986) The epizootiology and ecological significance of malaria in Hawaiian land birds. Ecol Monogr 56:327-344

Whited D, Galatowitsch S, Tester JR et al (2000) The importance of local and regional factors in predicting effective conservation: planning strategies for wetland bird communities in agricultural and urban landscapes. Landsc Urban Plan 49:49-65

Wilson S, LaDeau SL, Tøttrup AP, Marra PP (2011) Range-wide effects of breeding- and nonbreeding-season climate on the abundance of a Neotropical migrant songbird. Ecology 92:1789-1798 


\section{Affiliations}

\section{Vincenzo A. Ellis ${ }^{1,2} \cdot$ Michael D. Collins ${ }^{3}$}

$\triangle$ Vincenzo A. Ellis

vincenzoaellis@gmail.com

1 Departamento de Biologia Geral, Instituto de Ciências Biológicas, Universidade Federal de Minas Gerais,

Belo Horizonte, Minas Gerais, Brazil
2 Present Address: Molecular Ecology and Evolution Lab, Department of Biology, Lund University, Lund, Sweden

3 Department of Biology, Rhodes College, Memphis, TN 38112, USA 